\title{
INTERMANUAL TRANSFER OF TACTILE DISCRIMINATION
}

\author{
By: George F. Michel and Marsha R. Ovrut, and Debra Harkins
}

Michel, GF, Ovrut, MR, \& Harkins, DA. Intermanual transfer of tactile discrimination. Infant Behavior Development. 1984; 7:247. doi:10.1016/S0163-6383(84)80309-4

Made available courtesy of Elsevier:

http://www.elsevier.com/wps/find/journaldescription.cws home/620197/description\#description

\section{***Note: Figures may be missing from this format of the document}

Little is known about infant tactile discrimination, even though most sensory and motor innervation of each and is ,restricted to the contralateral hemisphere. In absence of interhemispheric transfer, mediated by he corpus callosum (a condition likely present in infants), tactile experience is potentially confined to one hemisphere. A head-turn conditioning procedure, used with 35 infants ( 7 - 14 mon.), assessed tactile discrimination. Two stimuli differing only in texture, were presented singly to infant's right hand. Five seconds later, an assistant appeared to "peek-a-boo". Each texture signalled the direction from which the assistant appeared. Overhead video-camera recorded infant's initial head turns. Directionally appropriate head turns for 2 consecutive trials suggested discrimination learning (which was assessed by 2 subsequent trials without the assistant appearing). Only $20 \%$ of infants learned the discrimination (mean number of trials $=16$ ). After learning, intermanual transfer was assessed by presentaion of stimuli in left (untrained) hand for 2 trials with directionally appropriate head turning indicating transfer of learned discrimination. No infant showed transfer although each showed directionally appropriate head turning during a subsequent final trial with the trained right hand. Infants seem not to transfer tactile experience between hemispheres until several months after their first year. Since infants manifest consistent hand-use preferences during their first year, one hemisphere will receive tactile experience quite different from, and not shared with, the other. 